\title{
THE IMPACT OF KNOWLEDGE WORK DESIGN: A FIELD STUDY IN THE SAUDI ARABIAN BANKING SECTOR
}

\author{
N. AL-ARRIFI \& A.I. BARAKAT \\ Shaqra University, Saudi Arabia.
}

\begin{abstract}
This study aims to spotlight the relationship between a knowledge society and a knowledge work design using a field study to explain ideas related to this field as culled from interviews, statistics and scientific references on the subject. There are many variables at play here. Independent variables indicating the character of knowledge societies include technological infrastructure, development and innovation systems, human resources and institutional governance, and dependent variables indicating the character of knowledge work design include the characteristics, skills and job status of knowledge workers. Data were collected using a questionnaire distributed to a sample of 150 individuals working in Saudi Arabian banks. The study yielded a set of results including a Pearson correlation coefficient between the dependent and the independent variables of 0.76 and a Pearson correlation coefficient of 0.70 indicating the relationship between technological infrastructure and knowledge work design. Moreover, the study results also indicate a meaningful impact of the independent variable on the dependent one: changes in the society studied will lead to variations in knowledge work design (again, including the characteristics of knowledge workers their skills and their job status). The results suggest the wisdom of encouraging, recruiting and developing skilled knowledge workers, if the goal is to achieve sustained human capital as a major source of knowledge capital for banks. Banks must also adhere to rules of institutional governance ensuring that they are managed and controlled to promote transparency and accountability in their work, abiding by laws and regulations to avoid financial and managerial corruption.
\end{abstract}

Keywords: banking sector, knowledge society, knowledge work design, technological infrastructure.

\section{INTRODUCTION}

Due to the rapid changes in the production of knowledge, technology and modern modes of communication, the last three decades have witnessed a growing need to explore the phenomenon of knowledge investment and consider how to develop highly qualified human resources. This trend has developed in tandem with the idea of the knowledge society, which is characterised by intellectual ownership, free access to information ease of handling and disseminating information, and the encouragement of creative initiatives on individual and institutional levels to ultimately allow the best possible use of information and our current knowledge. The hope is to use information to serve mankind, improving his quality of life in various domains through a new kind of social mobility. One important dimension of this effort that is emerging in developed countries is the production of knowledge and technology that is then adopted by other countries interested in market information and investment with a view toward creating an environment that will foster the development of both. Institutional readiness is a desired by-product of these efforts.

The influence of the knowledge society as well as the developments and challenges that have taken place within this context have put pressure on work structures and conditions. The question has arisen of what characteristics and skills workers should have in what is called knowledge work. Many researchers and specialists in human resources management have adopted that idea and the resulting changes have caused people to question of the components of traditional work design, especially because the knowledge society has produced a new understanding of the functions of knowledge workers. 
To address this problem and its dimensions in Saudi economic institutions, the current study will explore the status and the impact of its many dimensions and its implications for a knowledge society. The first step will be to record its quick steps on some financial service in the banking sector in particular.

\section{RESEARCH STATEMENT}

The goal of this research is to answer the following questions:

1. What is a knowledge society, and what are its characteristics, indicators and consequences?

2. What is working knowledge, and what does it include? What are its characteristics, and what cognitive and specialised skill knowledge are required for knowledge workers?

3. What are the study variables related to the knowledge society and knowledge work design?

4. Are there any significant correlations between knowledge society indicators and knowledge work design?

\section{STUDY SIGNIFICANCE}

The study is important in that it will do the following:

1. Build the fundamental knowledge capabilities of the high-tech industry as the basis for the competitive advantage of banks.

2. Help to facilitate the process of building human capital, one of the most important components of capital-knowledge banks.

3. Help to create a knowledge environment able to respond to the implications of the knowledge economy, on that is attractive and promotes in Saudi Arabia.

\section{STUDY OBJECTIVES}

Toward that end, the study aims to achieve the following specific objectives:

1. To present a theoretical overview of the knowledge society and knowledge work concepts in terms of the characteristics and skills associated with them as a basis for cognitive performance.

2. To explore the status of the knowledge society in the banking sector in Saudi Arabia and its impact on the characteristics and skills associated with knowledge work.

3. To provide a portfolio of indicators and benchmarks that can guide researchers and concerned individuals in determining the impact of knowledge society indicators in knowledge work design.

4. To bridge the gap indicated in the study problem.

\section{RESEARCH HYPOTHESES}

\subsection{First main hypothesis}

H0: There is no statistically significant relationship between indicators for the knowledge society and those for knowledge work design.

5.1.1 Sub-hypotheses that emerge from the first main hypothesis

1. There is no statistically significant relationship between technological infrastructure and knowledge work design. 
2. There is no statistically significant relationship between corporate governance infrastructure and knowledge work design.

3. There is no statistically significant relationship between human resources and knowledge work design.

4. There is no statistically significant relationship between innovation system and development and knowledge work design.

\section{SECOND MAIN HYPOTHESIS}

H0: Knowledge work design in the banking sector is not affected by changes in knowledge society indicators.

6.1 Sub-hypotheses that emerge from the second main hypothesis

1. The skills of the study sample are not affected by the changes that occur in knowledge society indicators.

2. The characteristics of the study sample are not affected by the changes that occur in knowledge society indicators.

3. The job level of the study sample is not affected by changes that occur in knowledge society indicators.

\section{STUDY MODEL}

Based on the theoretical framework at play with reference to relevant previous literature and according to the study objectives and variables, the researcher designed the study model as follows:

Knowledge society in Saudi Banking Sector

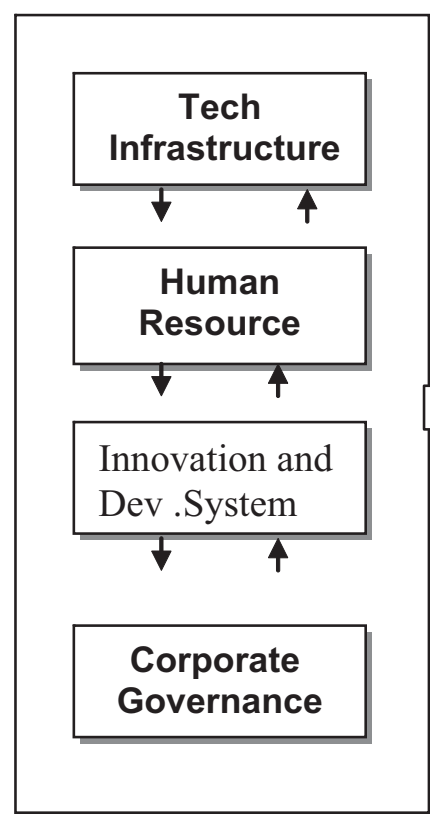

\section{Knowledge Work \\ Design}

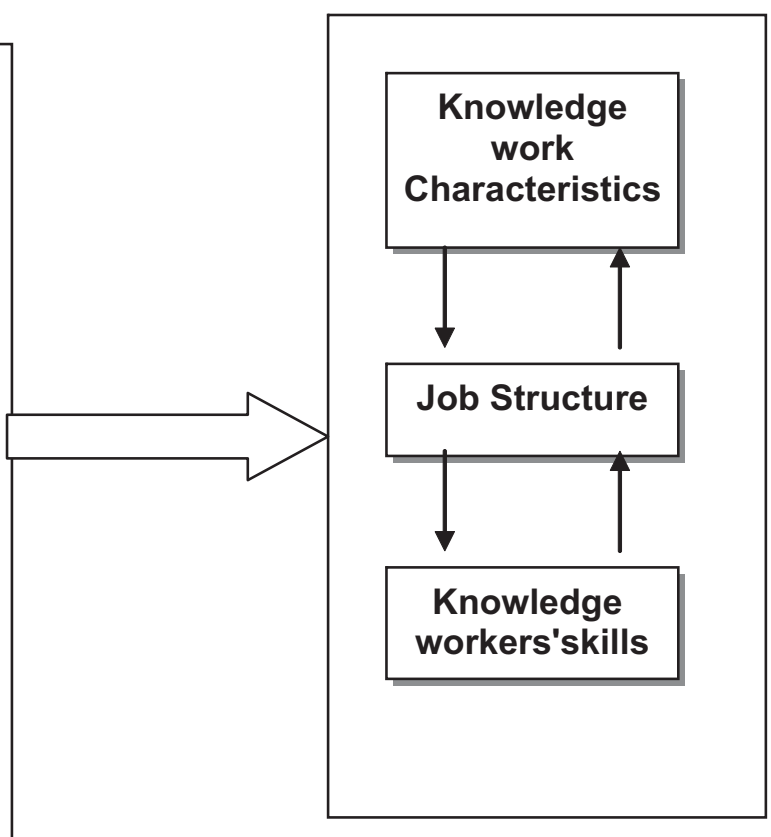




\section{RESEARCH METHODOLOGY}

To analyse and investigate the research problem, and to test the hypotheses, the researcher formulated specific indicators for the variables and designed an instrument, used to measure them, a questionnaire designed for this purpose. The following were included:

Four indicators for the independent variable (the knowledge society) with 19 scales.

Six indicators for the dependent variable, knowledge work design (including the characteristics and skills associated with knowledge work and job structure) with 19 scales.

Because of the importance of this aspect for researchers and professionals who are studying the 'knowledge society' as one of the leading subjects in the field of business administration and management information and financial systems, the researcher was interested in developing an abstract for this work for the sake of scientific and practical interest.

\section{KNOWLEDGE SOCIETY INDICATORS AND THE MEASUREMENT INSTRUMENT DESIGN}

The researcher conducted a preliminary survey using the Internet, choosing two sets of indicators for the purpose of characterising 'the national knowledge society.' They were as follows:

The first group/indicators and standards issued by the World Bank in 2006, including seven indicators with sub-80-measure [1].

The second group/indicators and standards presented at the Regional Conference on Communication and Information Technology held in New Zealand in 2004, including three indices with 40-measure [2].

For the purpose of this study, the researchers concentrated on four indicators derived from the above two groups. It is worthwhile to mention that the selected indicators are the best for Saudi case according to researches best knowledge and believe that such indicators are quite sufficient for Saudi case. The selection of the other six indicators is also for the same reason taking in consideration that Saudi situation is different. A set of measurements was designed for each group for the purpose of their evaluation with 19 measures included in total. The feasibility of taking these measurements and the availability of information were taken into account, as was the researcher's aim of providing a more precise description of the current reality in the Saudi banking sector. These indicators and the sequence of norms in resolution are illustrated in Table 1.

\subsection{Indicators of work knowledge design and the development of its measurement instrument}

Based on the general concept that was explained in research knowledge society, the researcher identified six general indicators based on which the characteristics, skills and career structure associated with knowledge work can be understood.

To ensure the proper use of these indicators and to verify their existence within the study sample population, a set of standards for each was developed according to their relative importance from researcher's point of view. Nineteen measures resulted from this process. These indicators and the sequence of their scales in the questionnaire are given in Table 2.

For procedural purposes in the questionnaire design and implementation process, all indicators and scales were consolidated and classified into three groups.

The first group: indicators associated with a knowledge society includes 19 statements listed in the questionnaire under paragraph two.

The second group: characteristics of knowledge work include 11 statements listed under paragraph three. 
Table 1: Indicators and measures of the independent variable (knowledge society).

\begin{tabular}{|c|c|}
\hline Indicators and measures & $\begin{array}{c}\text { Statements } \\
\text { sequence in } \\
\text { questionnaire }\end{array}$ \\
\hline \multicolumn{2}{|l|}{ The first indicator: corporate governance } \\
\hline 1-1 Bank's policies and work systems clarity and transparency of (7) & (7) \\
\hline 1-2 Documentation of workers' levels of duties and rights (8) & $(8)$ \\
\hline 1-3 Resort to procedures upon legal accountability (9) & $(9)$ \\
\hline $\begin{array}{l}\text { 1-4 Efficiency of administrative and financial corruption control } \\
\text { mechanisms (10) }\end{array}$ & $(10)$ \\
\hline \multicolumn{2}{|l|}{ The second indicator: human resources } \\
\hline 2-1 Clarity and transparency of recruitment procedures and standards (18) & (18) \\
\hline $\begin{array}{l}\text { 2-2 Number and type of training and rehabilitation programs available to } \\
\text { employees (16) }\end{array}$ & $(16)$ \\
\hline \multicolumn{2}{|l|}{$\begin{array}{l}\text { 2-3 Internal environment contributions to building a culture of knowledge and } \\
\text { information (15) }\end{array}$} \\
\hline $\begin{array}{l}\text { 2-4 Diversity of employment opportunities and level of economic and social } \\
\text { returns (11) }\end{array}$ & $(15)$ \\
\hline $\begin{array}{l}\text { 2-5 Degree of use of technological capabilities upon selection and work } \\
\text { continue (19) }\end{array}$ & $(11)$ \\
\hline \multicolumn{2}{|l|}{ The third indicator: innovation and development system } \\
\hline $\begin{array}{l}\text { 3-1 Institutional culture's contribution to encouraging creativity and } \\
\text { innovation (13) }\end{array}$ & $(13)$ \\
\hline $\begin{array}{l}\text { 3-2 The range of assistance provided to support study and development efforts } \\
\text { and results investing (14) }\end{array}$ & $(14)$ \\
\hline 3-3 Size of expenditure on scholarships for staff development (15) & $(15)$ \\
\hline $\begin{array}{l}\text { 3-4 Size of expenditure on purchases related to technological innovations to } \\
\text { develop banking system (12) }\end{array}$ & $(12)$ \\
\hline \multicolumn{2}{|l|}{ The fourth indicator: information and communication technology (ICT) } \\
\hline 4-1 Bank’s dependence on technology in providing its services (20) & $(20)$ \\
\hline $\begin{array}{l}\text { 4-2 Bank's success in keeping pace with developments in the field of electronic } \\
\text { services (21) }\end{array}$ & $(21)$ \\
\hline $\begin{array}{l}\text { 4-3 Infrastructural efficiency level for information technology and } \\
\text { communications (22) }\end{array}$ & $(22)$ \\
\hline $\begin{array}{l}\text { 4-4 System capacity and speed of electronic service networks used at } \\
\text { the bank(24/23) }\end{array}$ & $(24 / 23)$ \\
\hline $\begin{array}{l}\text { 4-5 Compatibility and harmony of technology used at the bank with } \\
\text { international standards (25) }\end{array}$ & $(25)$ \\
\hline
\end{tabular}

The third group: knowledge work skills includes eight statements listed in the questionnaire under paragraph four.

A five-point Likert scale was used to quantify the potential responses as follows (Table 3): Strongly agree, 5; Agree, 4; To some extent, 3; Disagree, 2; Strongly disagree, 1. 
Table 2: Indicators and measures of dependent variable (knowledge work design).

\begin{tabular}{ll}
\hline Indicators and measures & $\begin{array}{c}\text { Statements sequence in the } \\
\text { questionnaire }\end{array}$ \\
\hline 4- Creativity and innovation in knowledge work & 26.31 .37 \\
5- Participation based approach to knowledge work & 33.40 \\
6- The globalisation of knowledge work - content and & 28.29 \\
conditions & \\
7- Motivation and self-development of knowledge staff & 27.30 .32 \\
8- Knowledge workers ability to work with (IT) & 34.35 .36 .38 \\
9- Cognitive skills of knowledge workers (soft skills) & 39.41 .42 .43 .44 \\
\hline
\end{tabular}

\section{STATISTICAL ANALYSIS METHODS}

For the purposes of statistical analysis and hypothesis testing, the study used different methods, including the following:

Descriptive statistics.

Cronbach's Alpha reliability coefficients used to identify the internal consistency of questionnaire statements.

Means and standard deviations of the responses provided by the sample relation to indicators for the knowledge society, the independent variable, and the design of knowledge work the dependent variable.

Spearman correlation coefficients used to measure the relationship between the independent variable and the dependent variable.

Simple linear regression used to test the impact of the independent variable on the changes that occur in the components of the dependent variable.

Multiple regression coefficients used to test the impact of the independent variable (indicators for the knowledge society) on the changes that occur in the dependent variable (job design knowledge).

\section{QUESTIONNAIRE VALIDITY AND RELIABILITY}

To ensure the instrument's validity, the questionnaire was given to a panel of university staff and professionals and to bank employees who were subsequently excluded from the sample. Questionnaire reliability was tested using the reliability coefficient (Cronbach's Alpha), and the total reliability coefficient was (94\%). Thus, the questionnaire was deemed suitable for the analysis.

\section{POPULATION AND SAMPLING}

The study population consists of all commercial banks operating in the banking sector in Saudi Arabia, whether domestic or foreign. Approximately most of main headquarters of commercial banks are concentrated in Riyadh the capital; therefore, such central offices were deemed as the research population, taking into account the difficulties to reach other banks in different Saudi towns. The study sample consists of all employees at these banks who are considered knowledge workers (professionals, administrators and technicians). The sample size was 150 individuals, including 105 staff members at local banks and 45 at foreign banks, while the questionnaires are distributed equally among all knowledge workers with 50 people per group. 


\section{LITERATURE REVIEW}

\subsection{The knowledge society}

There is no consensus on the definition of a knowledge society, but there are a number of concepts that help to explain what a knowledge society is. Also, many terms are used nowadays that are equivalent to this one: for example, a knowledge society might also be called a post-industrial society, a learning society, a service community, an information community, an online community, paperless society, a digital society and a post-modern society [3].

The Okinawa Charter on Global Information Society states, 'Information technology and communications is one of the great underlying powers that contribute to shaping the 21st-century aspects, and reflects their impact on humans way of life, education and work, and an engine of global economic growth and meet the economic and social challenges more effectively. If there is a tremendous opportunity for us to seize and shared' [4].

The 2005 United Nations Educational, Scientific and Cultural report indicates that the information society results from a revolution in modern technology and that this is the only way to create a knowledge society. Network growth alone is insufficient because information is the means of developing knowledge, and is not tantamount to knowledge itself [5].

Among the most prominent examples of attention paid to this concept in the Arabic context was the announcement by the Arab Emirates States during the World Economic Forum at the Dead Sea - Jordan on May 19, 2007 that a fund of 10 billion dollars had been established to contribute to the effort to build a knowledge society in the Arab region.

We can say that knowledge society should has the group and the foundations of the properties that distinguish it from other communities and constitute its core, as agreed upon by researchers and those interested in the building this community. These characteristics are described below.

Knowledge is a component of production itself and influences the general characteristics of the other factors of production. It also affects changes in their specifications [6].

Knowledge is more important than capital and the labour force. It is the tool through which value is added, and it is important in most of all because it is the only resource that is not subject to the law of diminishing returns, and does not suffer from the problem of resource scarcity. It is the only abundant resource that builds cumulatively and does not decrease with use. By contrast, knowledge can be used to generate and develop new ideas inexpensively or even without additional cost [7].

Knowledge is no longer an element of production; it is treated as an encapsulated commodity sold and bought in a non-preceding manner. This is particularly true of, encoded knowledge [8]. The knowledge society reduces the gap between science and technology, where science becomes a directly productive force that has a strong impact on live in general [9].

Learning in a knowledge society is no longer limited to the traditional 18 - to 25 -year-old age group and is also no longer limited to the regular. Instead, this type of society gives the individual the freedom to learn by introducing new types of learning that higher education institutions have started to adopt. These include distance learning, alternative education, open learning education and online education[10]. E-learning is considered one of the main approaches here, with learning facilities based on electronic communication technology and self service technology to make knowledge available to those who are working instead of learning in the classroom [11].

The emergence of new patterns of management known as knowledge management involves the use of science, technology and tools to maximise intellectual capital value and activate institutional responses, revealing the best way for each organisation to generate knowledge and applications, deployment and retention [12]. 
Knowledge management can be defined as the management of critical knowledge that relies on the knowledge base, aiming to add value to work through regular operations such as diagnosis, acquisition, creation, storage, development, deployment and the application of knowledge throughout the company [13]. What distinguishes a knowledge society from an industrial society is that the factors of evolution, and results have the status of the public are not connected with a particular community [14].

The knowledge society has helped many virtual communities to emerge with community members who are geographically separated but who are united by benefits language and common interests [15]. Knowledge products, which are often intangible, are new distributed electronically in virtual markets through information networks like virtual universities, virtual shopping centres, virtual research centres, virtual workplace, virtual governments and virtual banks [16].

\subsection{Knowledge work}

Professionals have reported that the knowledge industry is becoming important for products, with raw materials, data, and human mind as their tools and knowledge as one of the components of any major economic system. Modern society uses knowledge to acquire new properties, and this has transformed knowledge from something that contributes to the proper use and handling of goods and services of strategic and economic value into a commodity in itself for customers. Thus, it has economic value and commercial markets that are the most popular and fastest growing in the world [17].

This is true especially because the technology industry is currently headed toward separating content knowledge (cognitive content) from its physical components, as is clearly shown in the realm of electronic equipment and that of electronic chips in particular. All realise that the knowledge industry is critical in the competition for dominance in the global market for the knowledge-based economy in the 21 st century, although the focus has thus far been on establishing the infrastructure for technology (equipment and networks) in a knowledge society [18].

Statistics show that $\mathrm{CD}$, which is produced currently the materials value in it do not form more than $1 \%$ of the cost, and the traditional manual work is also not more than $5 \%$ compared with the value of information and intellectual work, which was pressed in the work program of that disk, which constitutes the remaining amount 94\%). [19]. This development in the knowledge industry was accompanied by the emergence of two terms: knowledge work and knowledge workers. These terms have come to be used to refer to the jobs, professions and individuals employed in economic activities based on knowledge or what is sometimes called knowledge economies.

Knowledge workers are those individuals whose jobs are based on knowledge work and who interface with industries and other services in the 'hi-tech' industry, including communications and information technology (I-Tech) [20].

In this study, the focus will be on designing knowledge work according to its basic elements as follows.

\subsection{Knowledge work functional structure}

To clarify the professional status of knowledge work and the nature of the tasks associated with it both in states that have developed knowledge economies/societies and in the developing countries looking to develop this new type of society, a set of studies has been reviewed. The Canadian statistical center study was the most comprehensive in this field and was issued in two series: 2003 and 2004. [21]. 
Perhaps the most important results presented in these studies are those indicating that knowledge workers are distributors in all business sectors of the Canadian economy, but that the information technology and communications sector and the intensive knowledge-based industries occupy a greater share of the attention and make a greater contribution. The knowledge workers in the companies in this sector make up $84 \%$ of the total labour force, while the range is between $78 \%$ and $36 \%$ in other knowledge-based sectors, which is the same percentage recorded in most sectors of the USA economy, with statistics indicating that the ratio 4:1 at least of the workforce are knowledge workers. Indeed, this percentage has reached $90 \%$ especially in the formation and communication sector [22].

Statistics from the Organization for Economic Cooperation and Development (OCED) indicate that 8 out of 10 workers are knowledge workers, that is $80 \%$ [23]. In addition, the above-mentioned Canadian study identified 40 functional kinds of knowledge work included in the list of the functions of knowledge workers, classified into three functional categories are as follows.

\subsubsection{Professional occupations}

This category contains 20 functional titles, including the following positions: programmers, systems analysts, systems designers, artificial intelligence engineers, network engineers, engineers in all other disciplines, consultants, university professors, specialists in the natural sciences and medical specialists. They constitute the highest proportion of knowledge workers within the total amount of $50 \%$. They obtain high wages and hold specialised university degrees and more. The dominant feature of their work is that it is intelligent work involving production, the development of knowledge and the design of improvements to means of applying that knowledge.

\subsubsection{Directors: (management occupation)}

This category contains 11 functional titles, including directors of major administrative units in the areas of production, marketing, human resources, public relations and information systems. This category also includes legislators, lawyers and customer service representatives. They represent of $27.5 \%$ all knowledge workers, their wages had economic return and they mostly have college degrees. Their positions mainly involve management work and include management and organisation knowledge activities.

\subsubsection{Technical occupations}

This category contains nine types of positions and includes technical specialties ranging from engineering and medicine to agriculture and transportation and beyond. These professions form $22.5 \%$ of the total body of knowledge workers, and their wages are lower; they have diplomas or secondary school. Most of their work is manual.

On the basis of these statistics, the study shows that there is skills attraction, and demonstrate the increased value of intellectual work as compared with other types of work. There is an increase in white-collar positions at the expense of blue-collars workers in the field of knowledge work.

It can be concluded that the traditional employment pyramid, whose base consists of professionals, does not apply to institutions and industries based on knowledge work. However, it is reflected in this case, with the individuals who traditionally make up the broad base moved to the top. These individuals are the first category, specialists, and they are followed by the second category, managers, and then the third category is technicians. Figure 1 illustrates the structural position of knowledge workers as indicated in the above description.

In other words, we can say that leaders in the development of thought and knowledge occupy a greater share of the body of knowledge workers. Which is expressed by the elite IT and knowledge industry elite technocrats [24]? 


\section{CHARACTERISTICS OF KNOWLEDGE WORK}

The general characteristics of knowledge work are as follows.

14.1 The tendency to satisfy higher needs (advanced needs) at the expense of basic needs

This property is a new dimension of the personality of knowledge, and has revolutionised the concepts that make up Maslow's theory of 'work personal motivation' and needs ladder, which was built upon. It has been found that knowledge workers often experience pleasure in completing their work because they are working in positions consistent with their interests and abilities and enjoying their work time. As a result, the needs of knowledge workers are not necessarily as indicated by Maslow's hierarchy [25].

\subsection{Personal responsibility and self-development}

Knowledge workers are individuals who have the ambition and desire to work, and these workers constantly seek to acquire knowledge and their balance and abilities and in it. Therefore, the question of self-development and personal is deemed necessary and utmost need in the success of knowledge work.

\subsection{Self-management}

Self-management or personal management is one of the approaches that facilitate to the personal development and shape the personality show of independent knowledge workers.

\subsection{Sharing as a facet of knowledge work}

The sharing approach required in knowledge work is a mental process leading to a clearer understanding of common and effective processes among workers. Knowledge work seeks to promote the exchange of ideas and information among knowledge workers to create a workforce that is willing to accept new ideas from others and change according to these ideas.

\subsection{Globalisation of knowledge work}

It is clear that new kinds of occupations have emerged in recent years, as embodied by the concept of working remotely (Tele work). New economic reports show that there are specialised companies

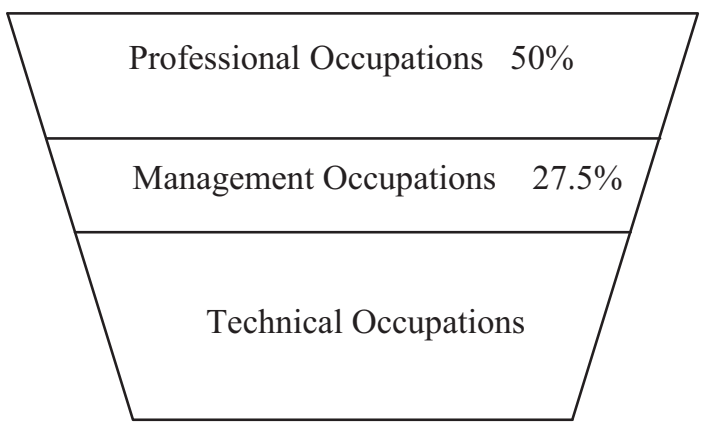

Figure 1: The structure of knowledge workers. 
working on marketing of knowledge products based on ideas and designs by other companies that themselves are working on product development. This is especially the case in the electronics industry [26].

\section{KNOWLEDGE SKILLS (SOFT SKILLS)}

A knowledge society cannot work at the operational level unless the two ends of the knowledge equation are addressed, the technology itself and the system of intellectual and knowledge workers. Thus, organisations are looking for knowledge workers who are able to perform a diverse set of actions throughout their careers without focusing on the completion of specific work. That is, the idea is to avoid excessive specialisation, requiring knowledge workers to be multi-talented because, they are not valued primarily based on their potential specialist and professional skills (hard skills) but are instead measured more on the basis of their potential intellectual and knowledge skills (soft skills), which help them to communicate information, acquire knowledge and master the tools to deal with that information and knowledge in the context of their specialisation. They also use these characteristics to manage and use modern technology to meet the requirements of knowledge work [27].

Encoded knowledge skills dealing and integration with becomes the most important capability for knowledge workers, along with the 'implicit' mentality that they should possess. Additional skills include creative thinking and knowledge-sharing communicating, with others in general, selfmanagement, time management, self-development and problem-solving [28].

\section{DATA ANALYSIS AND HYPOTHESIS TESTING}

\subsection{Demographic data analysis}

Overall, $90 \%$ of the sample is composed of males. This reflects the low participation rate of women, which is standard in this business. In other words, it reflects the reality of the Saudi community, which can be described as man community.

With respect to education level, the majority of the research sample $(60 \%)$ is made up of individuals with BSC degrees, which indicates that although the higher education rate is high, there are still some individuals who have only completed their secondary education. However, in our sample, there are also individuals who have had experiences working out-side Saudi Arabia, which reflects the strength of the Saudi market in its efforts to provide the human resources required to meet market needs in the banking sector. Overall, $90 \%$ of salary increases were for those whose salaries are 4000+ Saudi Riyals, which indicates that the salaries of knowledge workers are high compared with those of individuals working traditional jobs either in the banking sector or in other sectors. In considering the use of communication and information technology upon tasks implementation, one can see that $81 \%$ of the research sample uses Microsoft Office programs and the Internet for information exchange and communication, which in turn gives a positive indication of workers development in banking sector by using information technology in thief works implementation.

\subsection{Analysis of data related to study variables}

16.2.1 Analysis of responses addressing knowledge society indicators

As Table 3 shows, $89.23 \%$ of the individuals in the sample indicated awareness of the importance of knowledge society indicators, including technological infrastructure and institutional governance, 
Table 3: Relative and frequency distribution, means and standard deviations for the responses regarding knowledge society indicators $(n=150)$.

\begin{tabular}{|c|c|c|c|c|c|c|c|}
\hline \multirow{2}{*}{$\begin{array}{l}\text { Knowledge } \\
\text { society } \\
\text { indicators }\end{array}$} & \multicolumn{5}{|c|}{ Response scale } & \multirow[b]{2}{*}{ Mean } & \multirow[b]{2}{*}{$\begin{array}{l}\text { Standard } \\
\text { deviations }\end{array}$} \\
\hline & $\begin{array}{l}\text { Strongly } \\
\text { disagree }\end{array}$ & Disagree & $\begin{array}{l}\text { To some } \\
\text { extent }\end{array}$ & Agree & $\begin{array}{l}\text { Strongly } \\
\text { agree }\end{array}$ & & \\
\hline $\begin{array}{l}\text { Technological } \\
\text { infrastructure }\end{array}$ & - & 3.08 & 7.96 & 12.31 & 76.92 & 3.98 & 0.49 \\
\hline $\begin{array}{l}\text { Institutional } \\
\text { governance }\end{array}$ & - & 3.08 & 7.70 & 4.62 & 84.69 & 3.91 & 0.49 \\
\hline $\begin{array}{l}\text { Human re- } \\
\text { sources }\end{array}$ & - & 4.61 & 6.15 & 6.15 & 83.1 & 3.86 & 0.44 \\
\hline $\begin{array}{l}\text { Creativity } \\
\text { system }\end{array}$ & - & 3.5 & 6.90 & 7.32 & 82.1 & 3.80 & 0.46 \\
\hline Percent average & - & 3.54 & 7.17 & 7.69 & 81.54 & & \\
\hline \multicolumn{6}{|c|}{ General average and general standard deviation } & 3.91 & 0.47 \\
\hline
\end{tabular}

human resources and innovation systems. Only $7.17 \%$ of respondents are unsure of their answer and $3.54 \%$ of individuals strongly disagree that a knowledge society is important; however, the relative importance that the study sample attributes to knowledge society indicators shows the degree of importance according to sample perspective toward these indicators. The general mean (3.91) and general standard deviation (0.47) indicate this.

16.2.2 Analysis of responses related to knowledge work design

Table 4 shows that $63 \%$ of the study participants, in their answers addressing the concept of knowledge work design, demonstrate awareness of the importance of the skills, characteristics and functional levels associated with knowledge work design. The other $36.92 \%$ of the study sample was not sure or neutral in their responses. The relative importance of knowledge work design as indicated by the study sample and participants' perspectives on this concept are visible in the general mean (3.88) and general standard deviation (0.43).

\section{HYPOTHESES TESTING}

\subsection{Test of first major hypothesis}

H0: There is no statistically significant relationship between the knowledge work design and the knowledge society indicators.

To determine whether there is a statistically significant relation between knowledge society indicators and knowledge work design a test was conducted using the Spearman correlation coefficient, whose value was 0.70 . The calculated value was 7.46 , which is more than the tabulated value of 2.01, and this confirms the rejection of null hypothesis 1 and indicates that we must accept the alternative hypothesis: that there is a significant correlation between these two variables (Table 5).

To determine the relationship between the knowledge society indicators and the knowledge work design, the sub-hypothesis was tested as follows: 
Table 4: Relative distribution, means and standard deviations of the responses regarding knowledge work design $(n=150)$.

\begin{tabular}{|c|c|c|c|c|c|c|c|}
\hline \multirow[b]{2}{*}{$\begin{array}{l}\text { Knowledge } \\
\text { work design }\end{array}$} & \multicolumn{5}{|c|}{ Response scale } & \multirow[b]{2}{*}{ Mean } & \multirow[b]{2}{*}{$\begin{array}{l}\text { Standard } \\
\text { deviations }\end{array}$} \\
\hline & $\begin{array}{l}\text { Strongly } \\
\text { disagree }\end{array}$ & Disagree & $\begin{array}{c}\text { To some } \\
\text { extent }\end{array}$ & Agree & $\begin{array}{l}\text { Strongly } \\
\text { agree }\end{array}$ & & \\
\hline Characteristics & - & - & 87.69 & 12.31 & 28.2 & 3.81 & 0.33 \\
\hline Job levels & - & - & 12.31 & 87.69 & 25.3 & 3.88 & 0.33 \\
\hline Skills & - & - & 10.77 & 4.65 & 31.2 & 3.86 & 0.64 \\
\hline Percent average & - & - & 36.92 & 34.87 & 28.20 & & \\
\hline \multicolumn{6}{|c|}{ General average and general standard deviation } & 3.88 & 0.43 \\
\hline
\end{tabular}

Table 5: Spearman correlation coefficient for knowledge society indicators and knowledge work design.

\begin{tabular}{lccc}
\hline Variables & Calculated T & R2 & Relation \\
\hline Technological infrastructure & 8.90 & 0.76 & Significant \\
Corporate governance & 6.50 & 0.65 & Significant \\
Human resources & 7.95 & 0.67 & Significant \\
Creativity system & 8.91 & 0.76 & Significant \\
\hline
\end{tabular}

Variable level 0.05 .

Degree of freedom 0.63 .

1. In the first sub-hypothesis test, the relationship between technological infrastructure and knowledge work design was explored. A Spearman correlation coefficient test to determine was used the relationship between these two variables. It was clear that the calculated T value (8.90) is greater than the tabulated $\mathrm{T}$ value (2.01). This indicates that there is a strong and significantly positive correlation between technological infrastructure and knowledge work design at a 5\% significance level and 63 degrees of freedom of, as shown in Table 6. This result confirms the alternative hypothesis that is there is a significant correlation between the two variables.

2. In the second sub-hypothesis test, the relationship between institutional governance and knowledge work design was examined.

Based on this test, it emerges that $\mathrm{R} 2=0.65$ and that the calculated $\mathrm{T}$ value of 6.51 , which is greater that the tabulated $\mathrm{T}$ value of 2.01. This indicates that there is a significant correlation between these two variables, which confirms the alternative hypothesis: there is a relationship between the two variables.

3. The test of the third sub-hypothesis test was meant to explore the relationship between human resources and knowledge work design.

Based on this test, it emerges that $\mathrm{R} 2=0.67$ and the calculated $\mathrm{T}$ value is 7.95 which is more that the tabulated $\mathrm{T}$ value of 2.01 . This indicates that there is a significant correlation between these two variables, which confirms the alternative hypothesis that there is a relationship between the two variables. 
Table 6: Multiple regression analysis for knowledge society indicators and knowledge work design.

\begin{tabular}{lcccccc}
\hline \multirow{2}{*}{ Variable } & B & Std. E & Beta & Sig & F & F \\
\hline Knowledge society indicators & 0.63 & 0.10 & 0.86 & 0 & 4.5 & 3.17 \\
Knowledge work design & 0.57 & 0.21 & 0.41 & 0 & & \\
\hline
\end{tabular}

4. The test of the fourth sub-hypothesis examined the relationship between innovation systems and knowledge work design.

Using the test of this hypothesis, we find that $\mathrm{R} 2=0.76$ and that the calculated $\mathrm{T}$ value of 8.90 is greater that the tabulated $\mathrm{T}$ value of 2.01 , which indicates that there is a significant correlation between these two variables. This confirms the alternative hypothesis, that there is a relationship between the two variables.

It is evident based on the first major test of the hypothesis and its sub-hypothesis that knowledge society indicators, including technological infrastructure, human resources and corporate governance and innovation systems, have an active and prominent role in knowledge work design. In other words, the two components are closely linked.

\subsection{Second basic hypothesis test}

H0: There is no impact of changes to knowledge society indicators on knowledge work design in the banking sector.

Table 6 shows that the calculated value of $F$ is 4.5 , while the value of tabulated $F$ is 3.17 . Because the calculated value is more than the tabulated value at the level of $5 \%$ significance, we therefore, reject hypothesis $\mathrm{H} 0$ and accept the alternative one (H1), which indicates that knowledge work design is connected to knowledge society indicators in the banking sector.

It is clear from the tests done to examine the second hypothesis that there is knowledge society indicators including technological infrastructure, human resources and corporate governance and innovation systems, have a significant influence on knowledge work design. This includes an effect on its characteristics, skills and functional levels, indicating that any changes to these indicators will be reflected directly in knowledge work design.

17.2.1 The sub-hypotheses included under the second major premise H0: Study sample skills are not affected by changes that happen in knowledge society indicators.

The results of the simple regression analysis indicated in Table 8 show that the calculated F is 4.2 and the tabulated $\mathrm{F}$ is 3.14 . Because the calculated $\mathrm{F}$ is greater than the tabulated $\mathrm{F}$ at the 0.05 level, we reject the hypothesis and accept the second alternative sub-hypothesis, H1, which shows the impact of knowledge society indicators on those skills of the sample subjects that are associated with knowledge work design.

H0: Study sample characteristics are not affected by changes to knowledge society indicators.

The results of the simple regression analysis in Table 7 show that the calculated $\mathrm{F}$ is 4.9 and the tabulated F is 4.1 , and because the calculated F is greater than the tabulated at the level of 0.05 , we reject the hypothesis and accept the second alternative sub-hypothesis H1, which shows how the impact of knowledge society indicators in characteristics possessed by the sample subjects and associated with knowledge work design. 
Table 7: Regression analysis of knowledge society indicators and knowledge work design $\mathrm{N}=150$.

\begin{tabular}{lccccccc}
\hline & \multicolumn{4}{c}{ Standard coefficients } & & Calculated & Tabulated \\
\cline { 2 - 5 } Variable & B & Std. E & Beta & Sig & F & F \\
\hline Knowledge society indicators & 0.69 & 0.15 & 0.89 & 0 & 4 & 3 \\
Skills & 0.72 & 0.16 & 0.57 & 0 & 4.2 & 3.19 \\
Characteristics & 0.59 & 0.22 & 0.49 & 0 & 4.9 & 4.1 \\
Functional levels & 0.21 & 0.10 & 0.31 & 0 & 5.12 & 4.17 \\
\hline
\end{tabular}

H0: Study sample functional levels are not affected by changes in knowledge society indicators.

The results of the simple regression analysis in Table 7 show that the calculated $F$ is 5.12 and the tabulated $\mathrm{F}$ is 4.17 . Because the calculated $\mathrm{F}$ is greater than the tabulated at the $5 \%$ significance level, we reject the hypothesis and accept the second sub-alternative hypothesis H1, which shows how the impact of knowledge society indicators in functional possessed by the sample subjects and associated with knowledge work design.

\section{RESULTS AND RECOMMENDATIONS}

\subsection{Results}

Based on the results of this study in comparison with those of previous studies as noted in the literature review, a set of pertinent results can be presented:

1. Overall, $90 \%$ of the study sample was male. This indicates that the Saudi community is man society, which is in line with the (Hofsted, 1991) study of cultural dimensions across the world. In total, $60 \%$ of the individuals in the sample have a bachelor's degree which indicate that banks are keen to attract a high percentage of individuals with university degree, who are available on the Saudi market and wish to work at banks because of the incentives offered. The conclusion that such incentives exist is supported by the fact that $60 \%$ of the study has an income of more than SR 7000.

2. The results of the study indicate that $81 \%$ of the respondents use office software and internet communications in the exchange and dissemination of information (particularly Microsoft Office).

3. There is a strong statistically significant relationship between the knowledge society indicators related to technological infrastructure and the knowledge work design.

4. There is a moderate statistically significant relationship between human resources and knowledge work design.

5. There is a moderate statistically significant relationship between innovation systems and development, and knowledge work design.

6. The survey results show a moderately significant relationship between corporate governance and knowledge work design.

7. The survey results show that $89.23 \%$ of the study sample realises the importance of study population indicators including technological infrastructure, corporate governance, human resources and innovation systems in building knowledge as part of the banking work system. 
8. The study results indicate that $89.23 \%$ of the sample understands the importance of knowledge work design associated with the chrematistics, skills and functional levels of the study sample. This percentage is lower than the percentage who recognise knowledge society indicators as important to knowledge building.

9. There results indicate a highly significant impact of the study population indicators and knowledge work design, with any changes in study population indicators leading to changes in the variables for knowledge work design (characteristics, skills and functional levels).

\subsection{Recommendations}

Based on the above-mentioned results, the researcher recommends that Saudi banks and banks operating in Saudi Arabia do, the following:

- Adopt a knowledge-oriented organisational culture based on organisational learning that fosters creativity and innovation; additionally, adopt continuous learning practices and create supportive internal environment for continual learning.

- Increase scientific study and development provisions to upgrade the services provided to customers and increase scholarships for bank workers so that they can complete their graduate studies and specialised courses.

- Establish knowledge management at each bank, using information systems departments and their supporting technologies to cope with the complexities of a knowledge society.

- Concentrate on knowledge sharing and support work teams designed to provide new capital knowledge and employ it in the current knowledge context.

- Attract, develop, and maintain labour knowledge, including characteristics and knowledge skills, to ensure the sustainability of human capital, which is the most important component of capital knowledge at banks.

- Facilitate the experience of knowledge workers by giving them the power, strength and knowledge that will improve their ability to make decisions and solve problems.

\section{FUTURE RESEARCH}

Although the research used four selected indicators on the basis that they are the best for Saudi case, it is recommended that further researches should be made to use other indicators for the purpose of generalising the obtained results. Moreover, a further research has to be conducted with large sample size to cover all those concerned in knowledge society.

\section{REFERENCES}

[1] Knowledge Assessment Methodology - Variables and Clusters, http//www.worldbank.org, 2006.

[2] Australian Bureau of Statistics (Knowledge Based Economy and Society (KBE/S) Framework and Indicators) Asia-Pacific ICT Technical Meeting, Wellington, New Zealand, 2004.

[3] Toias Mueller - Prothmann, Knowledge Communities, Communities of Practice, and Knowledge Network Encyclopedia of Communities of Practice in Information and Knowledge Management, 2006.

[4] Abbas, Bashar (the role of e-economy in Arab Development and Economic Cooperation) Published study on the Website of the Arab Organization for Administrative Sciences, www. arado.org.eg, 2008.

[5] http://Poratunesco.org (Towards Knowledge societies - First UNESCO world Report), 2007. 
[6] David, P.A. \& Foray, D., Economic Fundamentals of the Knowledge Society, All Souls College: Oxford, OXI 4 Al, UK, 2002.

[7] Al-Omari Ghassan (information technology joint use and knowledge management to achieve a high value of Jordan commercial banks work) unpublished $\mathrm{PhD}$ thesis submitted to the Faculty of High Management Studies and Finance, Amman Arab University for Graduate Studies, Jordan, 2004

[8] Abdel-Wahid, Mohammed Najib Diab Asif (basic requirement for knowledge society) published study presented to Ninth Conference of higher education Ministers in the Arab World, Damascus, December 2003.

[9] Dahlman, J. et al., Finland as knowledge economy elements of success and lesson learned. International Bank for Reconstruction and Development/World Bank, 2005.

[10] Sahbani, Abdul Sattar (patterns of Higher Education Styles and their contributions in knowledge society construct) published a study submitted to the Ninth Conference of Higher Education Ministers in the Arab World, Damascus, December 2003.

[11] Brinkley, I. \& Lee, N., Knowledge Economy in Europe. Work Foundation, 2006.

[12] Abdel-Wahid, Mohammed Najib Diab Asif (basic requirement for knowledge society) published study presented to Ninth Conference of higher education Ministers in the Arab World, Damascus, December 2003.

[13] Al-Omari Ghassan (information technology joint use and knowledge management to achieve a high value of Jordan commercial banks work) unpublished $\mathrm{PhD}$ thesis submitted to the Faculty of High Management Studies and Finance, Amman Arab University for Graduate Studies, Jordan, 2004.

[14] http://ec.europa.eu (Employment and social Affairs Knowledge Society), 2007.

[15] Abdel-Wahid, Mohammed Najib Diab Asif (basic requirement for knowledge society) published study presented to Ninth Conference of higher education Ministers in the Arab World, Damascus, December 2003.

[16] http://www.egovmonitor.com, 2007.

[17] Drucker, P.F., Knowledge Work and Knowledge Society the Social Transformations of this Century, http://www.ksg.harvard.edu, 2004.

[18] Economist Print edition "Next Society", Nov 1st 2001.

[19] Hans - Dieter Eners, "Towards a Malaysian Knowledge Society” Third International Malaysian Studies Conference (MSC3) Binge, 2001.

[20] http://navcenter.borgess.com (Knowledge Worker Manual: What is a Knowledge Worker?), 2007.

[21] http://www.Statcan.ca/Dailty (The Daily Study: Knowledge Workers in Canada's Work Force, 2003).

[22] http://www.developmenteay.org (Knowledge Economy), 2007.

[23] http://www.Familtysearch.org (Man - Powering the Knowledge Economy), 2007.

[24] Abdel-Wahid, Mohammed Najib Diab Asif (basic requirement for knowledge society) published study presented to Ninth Conference of higher education Ministers in the Arab World, Damascus, December 2003.

[25] Andrew Herrington, Maslow'S hierarchy, societal change and the knowledge worker revolution, www.pateo.com, 2005.

[26] http://www.skyrme.com (Global Knowledge Economy), 2007.

[27] http://www.jpa.gov (Knowledge Workers), 2007.

[28] http://navcenter.borgess.com (Knowledge Worker Manual: What is a Knowledge Worker?), 2007. 